\title{
PRIMER CERTAMEN FRENOPÁTICO ESPAÑOL (1883): ESTRUCTURA ASISTENCIAL Y ASPECTOS ADMINISTRATIVOS
}

\author{
Olga Villasante Armas \\ Dra. en Medicina y Cirugia. Psiquiatra de la Unidad de Hospitalización Breve. \\ Instituto Psiquiátrico José Germain. Leganés. \\ Jose $\mathrm{M}^{\mathrm{a}}$ Roquero, 6, esc. 2, $7^{\circ} \mathrm{B}$ - Madrid, 28045. (España)
}

\section{RESUMEN}

En el último tercio del siglo XIX un grupo de profesionales de la Medicina trabajaba en NuevaBelén, hospital psiquiátrico localizado en las proximidades de Barcelona. Juan Giné y Partagás, director de este manicomio, y sus colaboradores, realizaban una labor clínica, académica y de investigación. Fue este grupo el que organizó la reunión más importante sobre Psiquiatría que tuvo lugar en el pasado siglo en España, en un momento en el que la especialidad no era, aún, reconocida como una disciplina cientifica independiente del resto de la Medicina.

El presente artículo describe la organización y contenidos del "Primer Certamen Frenopático Español" utilizando como material las actas originales del Congreso. Se centra en el análisis de las comunicaciones presentadas, cuyos contenidos temáticos son los aspectos administativos y asistenciales de la frenopatología de la época.

\section{SUMMARY}

In the latter part of the XIX century, an important group of physicians worked in Nueva Belén, a Mental Hospital located near Barcelona. Juan Giné y Partagás, the Director of Nueva Belén and his colleagues undertook investigation, clinical and academic work. This group organized the most important scientific meeting on Psychiatry in the last century in Spain, although Psychiatry had not yet been recognized as an independent science.

The present article describes the organization and contents of the "Primer Certamen Frenopático Español" using the original records. It is mainly focused on the Congress communications which deal with administrative and asistencial aspects of that time. 
La organización de congresos es, junto a la publicación de revistas especializadas, la creación de redes asistenciales, etc., uno de los aspectos importantes a considerar, en el proceso de institucionalización de una disciplina médica ${ }^{1}$.

En lo que se refiere a la Psiquiatría Española, si bien es cierto que no puede hablarse de una institucionalización "sensu stricto" hasta el siglo $\mathrm{XX}^{2}$, ya en las últimas décadas del siglo XIX pueden identificarse con claridad una serie de intentos de legitimación profesional y social de la medicina mental, sobre todo a partir de las iniciativas del "núcleo catalán" liderado por Giné y Partagás (1836-1903)33. Una de esas iniciativas fue, precisamente, el "Primer Certamen Frenopático Español" celebrado en 1883.

El objeto del presente trabajo, enmarcado en una investigación más amplia sobre dicho proceso institucionalizador, es analizar dicha reunión científica que agrupó a destacados frenópatas y legistas del último tercio del siglo pasado, centrándonos, principalmente, en las comunicaciones dedicadas a la estructura asistencial y aspectos administrativos de la psiquiatría de la época, por entender que es en el contenido de las mismas donde mejor pueden identificarse las ideas con las que los alienistas catalanes pretendían influir sobre la Administación Pública en materia asistencial.

1 Consúltese ROSEN G. (1944): The specialitation in Medicine with particular reference to ophtalmology, N. York; reimpreso en Arno Press and The New York Times, 1972. También puede consultarse Garcia BAlllester, L., OlagüE, G. y Ciges, M. (1978): Classic in Modern Otology, Granada. Sobre la institucionalización en paises europeos podemos destacar SCULL, A. (1991): "Psychiatry and Social Control in the Nineteenth Centuries", History of Psychiatry, 2, pp. 149-169 y acerca del proceso llevado a cabo en Francia el trabajo publicado por GoLDSTEIN, J. (1987): Console and Classify: The French Psychiatric Profession in the Nineteenth Century, Cambridge-New-York.

2 Para entender el proceso de institucionalización en España es clave el libro de ALVAREZ-URIA, F. (1983): Miserables y locos. Medicina mental y orden social en la España del XIX, Barcelona, Tusquets. También puede verse PERAZA DE AYALA, T. (1947): La psiquiatría española del siglo XIX, Madrid, CSIC, y la obra de ULLERSPERGER, J.B. (1954): La historia de la psicología y de la psiquiatría en Espa$\tilde{n} a$, desde los tiempos más remotos hasta la actualidad, Madrid, Alhambra (texto original de 1871), con prólogo, notas y apéndices de Vicente Peset.

3 DOMENECH Llaberia, E. y CORBElla CORBElla, J. (1969): "Las vertientes principales de la obra médica de Giné y Partagás", Actas del III Congreso Nacional de Historia de la Medicina, Valencia,1, pp. 174-5 destacan las figuras dominantes de esta generación en las que figura Robert, Valentí Vivó, Rodríguez Méndez y a las cuales atribuyen el brillo de la siguiente generación: Ferrán y Fargas, Barraquer y Cardenal, Jaime Pí y Suñer y Ramón Turró. Consultar también HUERTAS, R. (1994): "Los misterios de la locura: la popularización del concepto de alineación mental en la obra de Giné y Partagás (1836-1911"), comunicación presentada al seminario La Medicina en España y Francia y sus relaciones con la ciencia y la tradición y los saberes tradicionales (s. XVIII-XX), celebrado en Alicante los dias 13, 14, 15 de diciembre de 1994. 
PRIMER CERTAMEN FRENOPÁTICO ESPAÑOL (1883): ESTRUCTURA ASISTENCIAL Y...

\section{NACIMIENTO DE LA IDEA Y ORGANIZACION DEL CERTAMEN}

Un grupo de diversos profesionales presidido por Giné y Partagás ${ }^{4}$ anunció, en la primavera de 1882, la iniciativa de celebrar el Primer Congreso Frenopático Español, noticia publicada en junio en la Revista Frenopática Barcelonesa ${ }^{5}$. La posibilidad de organización de esta reunión científica, en un momento en el que el reconocimiento oficial de la disciplina era escaso, estuvo propiciada por el interés del grupo Giné en temas frenopáticos; grupo que desarrollaba una labor investigadora, docente y asistencial localizada en los alrededores de Barcelona y que dió lugar a la primera escuela psiquiátrica del país ${ }^{6}$.

A lo largo de todo el año 1882 , con caracter no oficial, los domingos por la mañana alumnos voluntarios de la Facultad de Medicina asistían a las lecciones impartidas por Giné en el Manicomio de Nueva Belén, situado en San Gervasio de Cassols, en las proximidades de Barcelona ${ }^{7}$. El Dr. Rodríguez y Rodríguez (1863$1937)^{8}$ recordó en el discurso de la primera sesión del Certamen las circunstancias

4 GraCIA, D.(1971): "Medio Siglo de Psiquiatría Española: 1885-1936", Cuadernos de Historia de la medicina Española,10, pp. 305-309. destaca: "la labor más importante de Giné como psiquiatra es que intentó poner en marcha un grupo relativamente homogéneo de colaboradores de su manicomio de Nueva Belén y de su revista. Allí se fraguó la primera escuela. Los nombres de A. Galcerán Granés, Rodríguez Morini, Ribas Pujol, Martí y Juliá, Moles y de su hijo Giné Marriera figuran entre sus discipulos. Sobre Giné vease también SANCHO SAN ROMAN, R. (1960): La obra psiquiátrica de Giné y Partagás, Salamanca, Ed Seminario de Historia de la Medicina de la Universidad de Salamanca.

5 Sobre dicha publicación se puede consultar CORBEllla CORBELla J., DOMENECH LlabERIA, E. (1965): "La Revista Frenopática Barcelonesa y el Manicomio de Nueva Belén", Bol. Inf. Inst. Méd. Psicol., 64, pp. 9-16. También véase REY GonZALEZ, A. M. (1985): "Clásicos de la Psiquiatría Española del siglo XIX: Arturo Galcerán Granés (1850-1919)", Rev. Asoc. Esp. Neuropsiquiatría, 5, 13, pp. 223 233. En enero de 1881, Giné y Partagás, con la colaboración de sus discípulos, comienza a dirigir la publicación de la primera revista de la especialidad, Revista Frenopática Barcelonesa. A pesar de su corta existencia (1881-1885), es considerada de un nivel científico estimable y la más importante de la pasada centuria. Más tarde, en 1903, Rodríguez Morini pretende darle continuidad y un carácter nacional fundando la Revista Frenopática Española.

6 Giné es considerado el fundador de la primera escuela psiquiátrica. Es, además, el autor del primer tratado español de psiquiatría publicado en España: GINÉ, J. (1876): Tratado Teórico-práctico de Frenopatología o estudio de las enfermedades mentales, cuyo subtítulo es fundado en la clínica y en la fisiología de los centros nerviosos, Madrid, Moya y Plaza. Este amplio volumen de al menos 500 páginas refleja la influencia de autores del positivismo francés, así como de Guislain, del que se encuentra bastante cercano ideológicamente y en cuya clasificación se basa para el estudio monográfico de la alienación mental.

7 Algunos autores han destacado esta enseñanza "libre", junto a una iniciativa similar de José María Esquerdo en Madrid, como lo que constituye el germen de lo que podría ser una enseñanza universitaria. Véase GrACIA, D., (1971), p. 314. También puede consultarse DOMENECH, E. y CORBELLA, J. (1969).

8 El Dr. Rodríguez y Rodríguez, médico interno del Manicomio de Nueva-Belén, es el secretario del Certamen. Sus publicaciones son firmadas en años posteriores como Rodríguez Morini, nombre por 
del surgimiento de la idea durante la celebración del final de dicho curso: "los discípulos reunidos alrededor del Dr. Giné, celebraban el final de las lecciones, en mayo de 1882, surgiendo en el momento álgido de la fiesta"9. Allí se nombró la "junta iniciadora"10, que comenzó a trabajar a partir de esta fecha, y el 10 de diciembre de ese mismo año se llevó a cabo la primera convocatoria firmada por los doce miembros de la Comisión Organizadora ${ }^{11}$. En esta convocatoria aparecían las bases del concurso y se expresaba la necesidad de la celebración de una Asamblea Científica de forma que ésta sirviese como modo de comunicación recíproca de conocimientos clínicos y terapéuticos, contrastados por la experimentación. Se reclamaba la concepción de una especialidad clínica para la disciplina, imprimiéndole un carácter independiente y una identidad nacional.

A pesar de la idea inicial de organizar un Congreso, ésta quedó reducida a un más modesto Certamen sobre Patología y Clínica Mentales, al no hallar ni medios económicos, ni apoyo oficial, para realizar la idea originaria. Se inauguró el 25 de septiembre de 1883 con el discurso del Dr. Giné y se prolongó hasta el 28 de septiembre, coincidiendo su clausura con la festividad de la Merced en Cataluña ${ }^{12}$.

\section{OBJETIVOS Y CONTENIDOS DEL CONGRESO}

La primera intervención del presidente, puede recordar a los textos literarios por su retórica prosa sin, por ello, perder un alto valor crítico, tono mantenido posteriormente por otros conferenciantes: "...El Certamen que hoy inaguramos, viene a ser una prótesis incruenta, con la cual nos proponemos, si no corregir, al menos disimular una horrible deformidad por defecto de sustancia, en la enseñanza oficial. Aquí

\footnotetext{
el que se le identifica en los círculos psiquiátricos. Fundador y director de la Revista Frenopática Española (1903-1905) que nace para dar continuidad y una identidad nacional a la $R F B$. Sobre el autor puede consultarse CALBET, J.M. y CORBELLA, J. (1970): "La obra psiquiátrica del Dr. Antonio Rodríguez Morini", Act. I CIHMC, III, pp. 318-325.

9 RoDRíGUEZ Y RoDRíGUEZ, A. (1884): " Memoria de los trabajos de la Comisión Organizadora" en Primer Certamén Frenopático Español, Barcelona, Establecimiento tipográfico "La Academia" de E. Ullastres, p. 30.

10 La junta iniciadora estuvo formada por Giné, Galcerán y Granés, Ribas, Laporta, Rodríguez, Azcarreta, Millares, Llansó y Gelabert que comienzan a trabajar a partir de la primavera de 1882.

11 La Comisión Organizadora consta del presidente Dr. Giné y varios colaboradores hasta completar el número de doce: Mariano Batllés y Bertrán de Lys, Joaquín Bonet y Amigó, A. Galcerán, P. Ribas Pujol, Prudencio Sereñana, José Fraxedas, Victor Azcárrate, Victoriano Gelabert, Joaquín Martínez, Jacinto Laporta y Antonio Rodríguez.

12 La comisión organizadora explica el hecho de la coincidencia de la festividad de la Merced con el Certamen en orden a buscar un símil y denominarlo "festividad científica"
} 
PRIMER CERTAMEN FRENOPÁTICO ESPAÑOL (1883): ESTRUCTURA ASISTENCIAL Y...

bajo la democrática y familiar forma de conferencias, aspiramos a trasfundirnos conocimientos que en vano buscaríamos en las cátedras del Estado"13.

Destacó Giné, la falta de cátedras, y el desconocimiento de las enfermedades de la mente tanto por los profesionales de la medicina como por el cuerpo judicial, el otro gran colectivo invitado al Congreso. Señaló las dificultades de magistrados, jueces, abogados y fiscales para fundamentar sus defensas o acusaciones, al carecer, también, de enseñanza jurídica en las universidades, y con ello, les instó a aunar sus esfuerzos con el cuerpo médico.

Tras una síntesis de la situación de la asistencia al enfermo mental justificó la elección del Hospital Psiquiátrico y de la ciudad de Barcelona como lugar privilegiado para celebrar el Congreso "... si los teólogos tienen sus conclusiones en una basílica ... si los higienistas, para sus grandes Congresos internacionales eligen las ciudades mejor higienizadas... i quién podría admirarse de que los frenópatas y legistas - dada la afinidad de sus estudios-nos hallemos científicamente reunidos en el seno de un manicomio?"14. El presidente del Certamen consideraba que el elevado índice de manicomios en Cataluña, tanto públicos como privados, traducía un mayor grado de civilización y la convertía en la cabecera científica del país. Esta característica favorecía la posibilidad de convocar a elementos médicos y jurisconsultos en Asamblea Frenopática "... El valioso concurso de eminentes médicos y jurisconsultos, así de la capital del Principado como de Madrid, Toledo, Valencia, París, Burdeos, Londres, Nueva-York, etc., "15.

Sin embargo, el autor resaltó a España como una entidad nacional "... donde debe reinar un solo consenso y una común aspiración: consensus unus, conspiratio una et omnia consentientia"16. Por ello, quizá, dicha intervención ha sido considerada por Josep $\mathrm{M}^{\mathrm{a}}$ Comelles al margen de un discurso catalanista no consolidado hasta varios años despues por Martí y Juliá17.

El Dr. Antonio Rodríguez y Rodríguez, secretario de la Comisión Organizadora, fue el encargado de exponer, tras el elocuente discurso de Giné, la "Memoria de los

13 GiNÉ, J. (1884a): "Discurso de apertura" en Primer Certamen Frenopático Español, Barcelona, La Academia, p. 18.

14 Ibid, p. 21.

15 Ibid, p. 24.

16 Ibid, p. 22.

17 La importancia de la Escuela Barcelonesa en el último tercio del XIX ha sido objeto de debate por destacados autores Véase COMELLES, J.M. (1988): "La asistencia psiquiátrica y desarrollo del estado en la España contemporánea" en La Razón y la sin Razón, Barcelona, PPU. pp. 110-114. El autor desta$\mathrm{ca}$, a propósito de esta intervención de Giné la relación del pensamiento nacionalista y el discurso psiquiátrico. Considera que el discurso catalanista no se hará evidente hasta varios años después de que Martí y Juliá, fundador del catalanismo de izquierdas, trate de utilizar sus ideas políticas como instrumento en la reforma de las estructuras de la asistencia psiquiátrica. 
trabajos de la Comisión". En esta comunicación se realizó una descripción del surgimiento de la idea del Congreso, ya comentado previamente, así como del modo en que se estableció el concurso de memorias. Giné ofreció mil pesetas para el autor del mejor trabajo sobre el tema: "Del idiotismo moral o sea del defecto ingénito del desarrollo de las facultades morales y afectivas en su relación con el Código Penal en España". Y así sucesivamente, los diferentes asistentes a la fiesta de fin de curso, fueron ofreciendo otros premios hasta un total de cuatro que debieron someterse a la opinión de un jurado ${ }^{18}$.

Los organizadores se lamentaron del reducido éxito del concurso, al cual sólo se presentaron un total de cuatro memorias ${ }^{19}$, optando una de ellas al primer premio, dos al segundo, ninguna al tercero y una al cuarto. El jurado no consideró que ninguna de ellas fuera merecedora de premio absoluto, si bien distinguió un mérito relativo a algunos de los trabajos presentados ${ }^{20}$. El propio tribunal expresó el deseo de mantenerse dentro del rigor científico ${ }^{21} \mathrm{y}$, posteriormente, autores como Domenech y Corbellá22 han ensalzado este hecho al considerarlo una prueba de la seriedad del tribunal. La escasez de trabajos, tanto en el plano cualitativo como cuantitativo, sirvió de reflexión a los miembros del jurado que lo atribuyeron a la deficitaria enseñanza en frenopatología, a la falta de medios de los profesionales y a la dificultad para acceder a los manicomios tanto por parte del foro como por parte de los estudiantes.

A. Rodríguez concluyó su discurso con una petición al Congreso para que éste aprobase una moción al Ministro de Fomento en la que se pedía que, en su trabajo de reforma del plan general de estudios médicos, incluyese la frenopatología como enseñanza oficial, teórica y clínica: "Hoy que el ministro de Fomento emprende este trabajo de reforma del plan general de estudios médicos, sería el momento más propicio para pedir, sobre todo por conducto tan autorizado como es este Congreso, la mejora que anhelamos. El Jurado suplica al Congreso tome en cuenta esta su moción"23.

18 El jurado estaba compuesto por Rafael Rodríguez Méndez, Jaime Pí y Suñer, Bartolomé Robert, A. Galcerán y Antonio Mola y Argemí.

19 A pesar de que en la "Memoria de los trabajos de la Comisión Organizadora" en Primer Certamen Frenopático Español (1884), p.33 puede leerse "... terminó el plazo, marcado de antemano, para su admisión, y solo cuatro acudieron a concurso..", DOMENECH, E. y CORBELLA, J. (1966): "El Primer Congreso Español (1883)", Bol. Inf. Inst. Méd. Psicol., 7, 82, pp. 9-14 describen: "... se presentaron solamente ocho trabajos.."

20 RODRíGUEZ y RODRÍGUEZ, A (1884), p. 41: " se le concede el mérito relativo a la única que optó al primer premio y a una de las presentadas al segundo premio y cuyo lema era "Consensus unus, conspiratio una et omnia in corpore consentientia".

21 Ibid, p. 36.

22 DOMENECH, E. Y CORBELLA, J. (1966)

23 RODRIGUEZ Y RODRÍGUEZ, (1884), p. 42. 
Las aportaciones al Certamen pueden dividirse en tres bloques temáticos: el clínico y terapéutico, el jurídico o médico legal y el administrativo o de organización asistencial ${ }^{24}$. Dada la imposibilidad de abordaje de todos los contenidos tratados durante los cuatro dias de celebración del Congreso, nos centraremos en el análisis de las intervenciones o ponencias relacionadas con temas de organización asistencial o administrativa, aunque no renunciamos a reseñar brevemente los contenidos de los otros dos bloques.

Las aportaciones clínicas y terapéuticas realizadas constituyeron el bloque más denso que abarcaba comunicaciones de diversa temática. Teniendo en cuenta que la Psiquiatría no estaba reconocida como disciplina médica independiente, no extraña la participación de profesionales de otras ramas, algunos prácticamente sin experiencia clínica en frenopatología. Destacaron, entre estos, Rodríguez Méndez (18451919) ${ }^{25}$, profesor de Higiene, Manuel Ribas y Perdigó, internista que presentó un trabajo de termometría cerebral, Francisco Rojo Batllé, catedrático de otorrinolaringología, aunque había optado también a la cátedra de Patología General, Freixas y Freixas, que sería, posteriormente, presidente de la Real Academia de Ciencias Médicas y Gil Saltor y Lavall (1862-1909) cuyo trabajo relacionó la causalidad entre las afecciones cardiacas y la vesanias.

Respecto al segundo bloque temático - la psiquiatría legal— estuvo representado por tres ponencias a cargo de Joaquin Bonet y Amigó, Alejandro Planellas y Arturo Galcerán Granés (1850-1919). Joaquín Bonet y Amigó, catedrático de Obstetricia en la Facultad de Barcelona, que llegó a ser rector de la Universidad, disertó sobre "Alteraciones psicopáticas durante el embarazo, responsabilidad de las embarazadas"26. Sostuvo que el médico-legista debía abstraerse del hecho del embarazo y realizar un examen exhaustivo de las facultades mentales de la mujer, para lo cual era necesario tener en cuenta otros factores como los antecedentes históricos, los antecedentes hereditarios y las circunstancias que precedieron o acompañaron al delito.

24 Esta distribución es también mantenida en DOMENECH LlABERIA E. y CORBELLA CoRBELLA J. (1966), pp. 205-206.

25 Rafael RoDRíGUEZ MÉNDEZ ( Granada,1845 - Barcelona, 1919) fue catedrático de Higiene de la Facultad de Medicina Barcelonesa desde 1874 a 1918, rector de la misma Universidad durante el período de gobierno liberal y editor de la Gaceta Médica de Cataluña. Aunque no fue específicamente frenopatólogo, tiene una importante obra psiquiátrica y fue director en el Manicomio de San Baudilio de Llobregat y en el de Reus, en ambos durante un breve período de tiempo. Para consultar más sobre el autor puede verse CORBELLA, J. y DOMENECH, E. (1983): "La obra psiquiátrica del doctor Rafael Rodríguez Méndez (1845-1919)", Comunicación presentada al Seminario de Historia de la Psiquiatría Española.

26 BONET Y AMIGO, J.: "Alteraciones psicopáticas durante el embarazo, responsabilidad de las embarazadas" en Primer Certamen Frenopático Español, Barcelona, La Academia, pp. 45-66. 
Alejandro Planellas Llanos, también obstetra, expuso "Alteraciones psíquicas en el histerismo y en las afecciones sexuales de la mujer - grado de responsabilidad en estos casos"27. Primero realizó un descripción clínica de las alteraciones, aceptando después los principios de Rossi descritos en su Tratado de Derecho Penal28, como condiciones de responsabilidad moral.

Arturo Galcerán Granés, médico consultor del Manicomio de Nueva-Belén, realizó dos comunicaciones: "El determinismo de la voluntad -El libre albedrío- Crítica de ambas doctrinas" 29 y "Responsabilidad parcial de los enajenados. Datos prácticos para conocerla y graduarla" 30 .

La importancia de este bloque, y fundamentalmente de las comunicaciones realizadas por Galcerán Granés, viene dada tanto por la extensión, como por la calidad del contenido. Giné y su escuela, cuyo mayor exponente es Galcerán Granés, es considerada precursora de la psiquiatría forense en España ${ }^{31}$. La calidad de estas ponencias, así como el prestigio de los ponentes, la convierte en una de las partes más brillantes del Congreso.

\section{UN INTENTO DE INFLUIR EN LA ESTRUCTURA ASISTENCIAL}

La disposición de las leyes que abarcaban la política sanitaria influía de un modo capital en los problemas asistenciales planteados por los frenópatas del siglo pasado, razón por la cual abordaremos más extensamente los aspectos administrativos trata-

\footnotetext{
27 Planellas, A. (1884): "Alteraciones psiquicas en el histerismo y en las afecciones sexuales de la mujer - grado de responsabilidad en estos casos" en Primer Certamen Frenopático Español, Barcelona , La Academia, pp. 55-66.

28 Pellegrino ROSSI (1787-1848) fue un político y juriconsulto italiano, asesinado en Roma en 1848, aunque parte de su carrera sería ejercida en la Universidad de Francia. En 1829, escribió su Traité de droit pénal, cuya primera versión al castellano sería realizada por Cayetano Cortés en 1839, Imprenta de Don José María Repullés, Madrid. Entre su obra podemos destacar Cours d'économie politique y Cours de droit constitutionel, además de numerosos artículos.

29 GALCERÁN, A. (1884a): "El determinismo de la voluntad - El libre albedrío - Crítica de ambas doctrinas" en Primer Certámen Frenopático Español, Barcelona, La Academia, pp. 67-96.

30 GALCERÁN, A. (1884b): "Responsabilidad parcial de los enajenados. Datos prácticos para conocerla y graduarla" en Primer Certámen Frenopático Español, Barcelona, La Academia, pp. 331- 403.

31 Sobre el particular, véase DOMENECH LLABERIA, E. Y CORBELLA, J. (1969), pp. 154-155, en la que se destaca la sólida formación y la amplia experiencia de Galcerán en temas de psiquiatría legal. En Madrid, el grupo iniciado por Pedro Mata, catedrático de Medicina Legal, y continuado por Esquerdo y Vera, también muestra gran inquietud por los problemas médico-legales del enfermo mental. Consultése, además HUERTAS, R. y MARTíNEZ, J. (1993): "Disease and crime in Spanish positivist psychiatry". History of Psychiatry, 4, 459-481 y VALENCIANO GAYA, L.(1974): Origen y desarrollo de la psiquiatría madrileña, Revista de Psicología General y Aplicada, XXXIX, 126, pp. 43-61.
} 
PRIMER CERTAMEN FRENOPÁTICO ESPAÑOL (1883): ESTRUCTURA ASISTENCIAL Y...

dos en el Certamen. Para su discusión nos hemos centrado en las ponencias de Giné, Ronquillo (1838-1900), Prudencio Sereñana, Rodríguez y Rodríguez y el neoyorquino E.C. Seguin (1843-1898)

De las cinco ponencias consideradas a estudio, el "Ensayo médico-administrativo sobre el ingreso, estancia y salida de los enfermos de la mente en los asilos públicos y privados"133, expuesto por Giné en la segunda sesión, constituye uno de los ejes centrales del Congreso.

Abordar un tema como el administrativo en una época en la que la atención prestada por el Estado no correspondía a las necesidades manifestadas por los profesionales no era una cuestión fácil. En este abordaje, Giné llegó a proponer un esquema de proyecto legislativo unificado que la Asamblea decidió, a petición de Galcerán, elevar al Excmo. Director General de Beneficiencia y Sanidad: "rogamos encarecidamente a dicha Autoridad se digne estudiar detenidamente este asunto y llevarlo a las Cortes para que en breve sea llenado un gran vacío que hoy en día se nota en nuestra legislación"34.

En el año en que se celebraba este acontecimiento la asistencia psiquiátrica en España se regía por la Ley de Beneficencia de 1849, según la cual, se establecía que cada manicomio debía poseer un Reglamento propio aprobado por el Ministro de la Gobernación, el Director de Beneficiencia o el Gobernador de la Provincia. Este hecho provocaba una disparidad de procedimientos administrativos entre los diversos manicomios, lo que constituyó uno de los motivos de crítica de Giné, quien exortó a la Administración Pública a modificar las Leyes de modo que no pudieran inferirse daños en los alienados.

La Ley de Beneficencia de 1849 y el Reglamento para su ejecución de 1852 instauraron la Beneficiencia Pública y normalizaron las funciones de los establecimientos públicos generales a los que pertenecían los establecimientos de los locos, consagrando el caracter subsidiario del Estado en este asunto. Esta ley, en vigor hasta bien entrado el siglo XX, no pretendía reformar el sistema asistencial vigente, sino acabar con la mendicidad y moralizar los socorros. Sucesivos intentos guberna-

32 E. C. Seguin, hijo del conocido alienista francés Onèsime Edouard Seguin, nació en París en 1848, emigró a los cinco años a New York, ciudad donde morirá en 1898. Fundó la Sociedad de Neurología de Nueva York y la Asociación Americana de Neurología. Contribuyó al esclarecimiento de la patología espinal, así como a la terapéutica de estas enfermedades, debiéndosele a éste la introducción del Iodo en el tratamiento de las mismas. Fundó American Series of Clinical Lectures en las que publicó importantes trabajos sobre la Anatomía Patológica del Sistema Nervioso, localizaciones corticales, mielitis y neuralgia.

33 GINÉ, J. (1884b): "Ensayo Médico-administrativo sobre el ingreso, estancia y salida de los enfermos de la mente en los asilos públicos y privados" en Primer Certamen Frenopático Español, Barcelona, La Academia, pp. 147-172.

34 Ibid., p. 172.

Asclepio-Vol. XLIX-1-1997 
mentales no fueron sino medidas paliativas: una circular de la Dirección General de Beneficiencia y Sanidad del 5 de julio de 1864 que recomendaba la ampliación y mejora de las instalaciones de dementes; una Orden Circular de la Regencia del 27 de julio de 1870 en la que el Gobierno transfería provisionalmente su responsabilidad en la asistencia de los alienados a las Diputaciones; y un Real decreto de 27 abril de 1875 en el que regulaba la inspección de los establecimientos benéficos, tarea hasta entonces encomendada a los gobernadores de la provincias, pero que resultó tan poco operativa como la antigua ${ }^{35}$.

Ante la desorganización y la falta de efectividad administrativa, Giné propuso en su ponencia unas disposiciones prácticas que dividió en tres partes en su exposición. En la primera parte, "Del derecho de los locos a ser considerados y cuidados como enfermos" 36 , describió el término alienado: "Hoy día los alienados son enfermos a quienes aflige un mal mayor que el tifus, la peste y la gangrena .... miembros del cuerpo social, desvalidos, a quienes les falta el principal apoyo y el arma más poderosa para luchar contra las necesidades orgánicas y los embates del mundo cósmico y social: la razón"137. La tendencia a considerar al loco como un pecador, un poseso, un profeta.... todavía era una idea sostenida, en el siglo XIX, por gran parte de la población ${ }^{38}$, por lo que Giné pretendió con esta definición, antes de comenzar la parte dispositiva del Proyecto, una clarificación del concepto de alienado. Describió sus derechos, así como los del resto de los ciudadanos en relación a los dementes.

En una segunda parte, "Del derecho de los ciudadanos a ser preservados de los daños y perjuicios que a sus personas e intereses puedan causar los locos ${ }^{39 "}$, expuso cómo el Estado tenía, asimismo, la obligación de evitar las molestias y perjuicios de la locura, y no abandonar esta función sólo al cuidado de la familia insistiendo, una vez más, en que "La salud pública es suprema ley"40. Las autoridades administrativas deberían adquirir el derecho y el deber de procurar la libertad de aquellos con la mente imperfecta o insegura. Resaltó, así, al Manicomio como principal agente terapéutico ".... éste es el lugar en donde hallará cuanto su enfermedad requiere: razón tranquila, criterio clínico, alimentación sana, medicamentos, baños, duchas, y si son

\footnotetext{
35 Consultar al respecto ESPINOSA IBORRA, J. (1966): La asistencia psiquiátrica en el siglo XIX, Valencia, Cátedra e Instituto de Historia de la Medicina. Véase también BERTOLIN, J.M. (1993): "Dispositivos de asistencia psiquiátrica en la España contemporánea del período de entresiglos", Asclepio, 45, 1, pp. 189-215. Este último autor realiza una descripción del marco legislativo general.

36 GINÉ, J. (1884b), pp.149-154.

37 Ibid, p. 49.

38 En este sentido apunta otra de las comunicaciones del Congreso: LAPORTA Y MERCADER, J. (1884): "Distinción práctica entre la pasión y la locura" en Certamen Frenopático Español, Barcelona, La Academia, pp. 275-281.

39 GINÉ, J. (1884b), pp. 155-159.

40 Ibid., p. 158.
} 
necesarios, adecuados y suaves medios de sujección y de contención, para que no se lastime o se mate" 41 .

En este mişmo sentido apuntó otra de las ponencias agrupadas en este bloque y defendida por D. Prudencio Sereñana y Partagás, "Estética de los manicomios y condiciones que deben tener" ${ }^{\prime 42}$. Sereñana, sobrino de Giné y Partagás y más conocido posteriormente por las traducciones de la obra médico-legal de Ambroise Tardieu, realizó una descripción tanto de las condiciones ambientales exteriores y de ubicación que deberían tener los sanatorios mentales, como del equipamiento interno. Enumeró aquellos recursos terapéuticos necesarios en el establecimiento: farmacológicos, higiénicos, local hidrológico y aparatos eléctricos de faradización. Este autor proclamó el sistema mixto ${ }^{43}$, frente al sistema non-restraint ${ }^{44}$ defendido por Giné y que Sereñana consideraba imposible de implantar en su forma más pura.

En la tercera parte de su exposición: "Del derecho que tienen las personas de juicio sano a que se las preserve de ser tratadas como alienados"45, realizó Giné una descripción de lo que el alienista debía ser y conocer, de modo que si el Director de un Manicomio, máximo representante de la Psiquiatría, cumpliera honestamente con su trabajo no debería permitir que se privase de libertad a ningún cuerdo.

\footnotetext{
41 Ibid., p. 158.

42 SereñANA, P. (1884): "Estética de los manicomios y condiciones que deben tener" en Primer Certamen Frenopático Español, Barcelona , La Academia, pp. 257-268.

43 Sereñana, en la exposición de la ponencia, defiende el SISTEMA MIXTo como método ideal a adoptar: " empleo de todos aquellos medios de sujección que, sin producir en los tegumentos del loco lesión de ninguna clase como puede acontecer con las ligaduras demasiado apretadas, ni herir el sentimiento de dignidad que experimenta el cuerdo ante la vista de medios contentivos fabricados con mucho hierro.." (SEREÑANA, P. (1884), p. 263). Explica cómo existen medios contentivos como la camisa de fuerza, pantalón de Parigot, cinturón, trabas y celdas fuertes acolchadas, que "... no exasperan el delirio del enfermo, ni ofenden la vista de la persona cuerda que se ve obligada a usarlos para el tratamiento de la locura" (Ibid., p. 264).

En la ponencia también se describen determinados coadyuvantes del tratamiento como los remedios morales, elementos higiénicos, una botica con todos los remedios farmacológicos, un local hidrológico y aparatos eléctricos de faradización; así como las condiciones de emplazamiento (terrenos secos y aptos) y la construcción del edificio (planta lineal compuesta). (Ibid., pp. 264-267).

44 Consultése al respecto la descripción de la implantación del non-restraint como principio terapéutico a lo largo de todo el XIX, en HUERTAS R. (1992): Del Manicomio a la salud Mental, Madrid, FIS, pp. 54-58. El sistema non- restraint, libertad casi absoluta, fue proclamado por Charleston y R. G. Hill a principios de 1829, en el asilo de Lincoln; aunque será J. Conolly el artífice de lo que en el mundo entero se conoció como non-restraint. Este lema fue adoptado por Giné desde el principio de la fundación del Manicomio, aunque, poco a poco, fue cediendo a una postura más ecléctica, en la que aceptaba algún medio coercitivo para casos especiales y de manera excepcional.

45 GiNÉ, S. (1884b), pp. 160-165.
} 
Posteriormente expuso " Parte dispositiva del proyecto de reglamento sobre el ingreso, estancia y salida de los locos de los manicomios públicos y privados"46. Este proyecto estaba compuesto por tres títulos que incluían la Dirección e Inspección del Manicomio, el ingreso y la salida del establecimiento. El primer título constaba de 13 artículos que podríamos agrupar en dos partes: los cuatro primeros indicaban las funciones de la Diputación, cuya reponsabilidad era la de fundar y sostener los Manicomios, la del Gobierno y Gobernadores Civiles y Dirección General de Beneficencia y Sanidad y los otros nueve atañían al cuerpo médico, tanto al personal mínimo necesario en cualquier establecimiento, como al modo de obtener sus plazas y el cobro de sus honorarios.

El segundo título añadía nueve artículos más, referentes a las condiciones necesarias para el ingreso de un alienado, que incluían la valoración clínica y diversos requisitos administrativos (solicitud, condición de pobreza..). Los documentos originales que constituirían el expediente de ingreso quedarían archivados en el Gobierno de la Provincia.

En el tercer título se enunciaban seis artículos más respecto a la salida de los Asilos que debería, a juicio de Giné, ser ordenada por la autoridad judicial o civil o por el médico Director, pudiendo ser promovida por los parientes más próximos. Su salida sería, además, comunicada al Gobernador Civil, expresando el estado en el que el enfermo abandonaba el hospital.

Galcerán Granés ${ }^{47}$, el más prolífico escritor de artículos sobre temas frenopáticos del siglo XIX ${ }^{48}$, fue el encargado de proponer la elevación íntegra de este ensayo de Reglamento al Excmo. Sr. Director General de Beneficiencia y Sanidad. El mismo Galcerán, posteriormente a la aceptación de la anterior propuesta, realizó una segunda petición de voto dirigida al Ministro de Fomento: "de modo que el estudio de la disciplina fuese obligatorio para todos cuantos optasen al título de licenciado"49. También esta cuestión fue aceptada por unanimidad y propuesta para el voto de los altos cuerpos legislativos.

La escasa atención que la Administración prestó al Certamen, y secundariamente a sus peticiones, no impidió que el eco de esta "festividad científica" llegase más allá

46 Ibid., pp. 165-171.

47 Se forma en el Manicomio de Nueva Belén junto a Giné y posteriormente será director de San Baudilio de Llobregat y co-director del Pedro Mata de Reus. Fundador de la Revista de Archivos de Terapéutica de las Enfermedades Nerviosas y Mentales y colaborador importante de la Revista Frenopática Barcelonesa, siendo autor de casi ciento cincuenta artículos y de nueve libros de psiquiatría. Fundador de la Sociedad de Psiquiatría y Neurología de Barcelona.

48 Así lo entiende REY, A. (1985): "Clásicos de la psiquiatría española del siglo XIX: Arturo Galcerán Granés (1850-1919)", Revista AEN, 5, 13, p. 226

49 GINÉ, J. (1884b), p. 172 . Esta proposición ya había aparecido anteriormente en el Certamen en la presentación de la "Memoria de los trabajos de la Comisión Organizadora", p. 42. 
PRIMER CERTAMEN FRENOPÁTICO ESPAÑOL (1883): ESTRUCTURA ASISTENCIAL Y...

de nuestras fronteras. El Congreso contó con la participación de autores extranjeros de gran prestigio como Magnan (1835-1916) y Régis (1855-1918) ${ }^{50}$, que presentaron en sendas comunicaciones una discusión psicopatológica sobre las alucinaciones y una propuesta terapéutica para sitófobos, respectivamente.

La aportación de E. Constancio Seguin, "Noticias sobre los Manicomios en España"51, que no acudió al Congreso y envió su aportación desde Nueva York, tiene un valor descriptivo histórico de parte de la situación manicomial de España. La comunicación del médico franco-americano estuvo basada en la información recogida, por él mismo, en un viaje realizado a España durante el invierno de 1882-1883 y fue traducida por el Dr. Gaspar Sentiñón (1835-1902) y leida en la cuarta sesión del congreso por el Dr. Rodríguez y Rodríguez.

En el trabajo, el autor destacaba la cordialidad con la que había sido tratado en todos los hospitales y la colaboración de sus colegas en todos los centros que visitó. Realizó una breve reseña de cada establecimiento visitado (prácticamente incluyó en su visita toda la geografía española, excepto la franja norte de España, Valladolid y Salamanca), una reproducción estadística, que él mismo describió como escasa e inútil, una opinión acerca del cuidado, tratamiento y los medios a emplear para una mejoría rápida, describiendo algunos de los métodos de sujección suaves (camisola o manillas de cuero blando).

A pesar de la amplitud de la información vertida se ha criticado su escaso valor como documento original ${ }^{52}$. Sin embargo, nos parece reseñable que más allá del contenido de la comunicación, la labor científica en el campo de la frenopatología fuese reconocida fuera de nuestras fronteras, en un momento aún muy lejano del reconocimiento oficial de la disciplina. Probablemente este hecho no hacía sino traducir la labor de una serie de profesionales como Mata (1811-1877), Pí y Molist (18241892), Giné, Rodríguez Méndez, Esquerdo (1842-1912), Galcerán, Vera (1859-1918) y Pulido, que como destacó Rodríguez y Rodríguez en su comunicación sobre "El estado actual de los conocimientos frenopáticos actuales en España"53, eran autores citados repetidamente fuera de nuestras fronteras (Francia, Belgica, Inglaterra, USA e Italia).

50 MAGNAN presenta "De las alucinaciones bilaterales de carácter diferente según el lado afecto", ponencia traducida por Alberto D. Gelabert. REGIS presenta el diseño de una bomba estomacal de doble corriente modificada para alimentación forzada de alienados sitófobos. La información del aparato había sido publicada en Annales Medico-Psychologiques en Enero de 1883.

51 SEgUIN: "Noticias sobre los manicomios", en Primer Certamen Frenopático Español, Barcelona, La Academia, pp. 429-465.

52 DOMENECH, E. y CORBELlA, J. (1966).

53 RoDRIGUEZ, A. (1884): "Estado actual de los conocimientos frenopáticos en España", en Primer Certamen Frenopático Español, Barcelona, La Academia, pp. 423-427. 
Coincidente con la crítica de los propios profesionales españoles asistentes al Congreso, E.C. Seguin expresó la queja generalizada de todos los médicos entrevistados durante su visita a las diversas instituciones: "los médicos se expresaron en términos asaz fuertes contra el descuido de las autoridades locales con respecto a los dementes"54.

El Dr. Rodríguez y Rodríguez, secretario del Congreso, leyó además de las aportaciones extranjeras (la de Desmaisons en nombre de Régis y la de E. C. Seguin traducida por Gaspar Sentiñón) la, ya nombrada, aportación original sobre "El estado actual de los conocimientos frenopáticos en España". El objetivo de la comunicación fue poner de manifiesto el atraso de la formación médica en temas frenopáticos y el malestar subsiguiente de los profesionales, asunto del que ya se había hecho eco E.C. Seguin.

Ronquillo y Morer presentó "El Manicomio del presente y del porvenir"155, comunicación en la que estableció las analogías entre las vesanias y la vida fisiológica y patológica del niño, sintetizado en: "si el manicomio ha triunfado hoy de la superstición, la ciencia frenopática debe ser vencedora mañana de las preocupaciones sociales: debe guiar y corregir la humanidad desde la infancia"56.

\section{ClAUSURA Y CONCLUSIONES}

El discurso de clausura fue pronunciado el 28 de septiembre de 1883 por Giné y Partagás. En éste, se agradeció la presencia de Juan de Rull, decano de la Facultad de Medicina de Barcelona ${ }^{57}$, y se expresó la confianza en la prensa, como arma de difusión de los pensamientos ${ }^{58}$.

En la intervención de Giné se destacó que la filosofía del Congreso y, en general, del espíritu que había movido el desarrollo de la escuela catalana, era la clara dependencia del pensamiento francés: "los médicos catalanes ... reinan las sanas doctrinas del positivismo y de la observación clínica, templada en el criterio biológico experimental, al que dió vida contemporánea el eminente Claudio Bernard"59. Describió la

\footnotetext{
54 SEGUin, E. C. (1884); p. 429.

55 RONQUillo, C. (1884): "El manicomio del presente y del porvenir", en Primer Certamen Frenopático Español, Barcelona, La Academia, pp. 201-211.

56 Ibid., p. 201.

57 Juan de Rull, junto al Dr. Emilio Pí y Molist, médico alienista del Hospital de Santa Cruz, y al Dr. Desmaisons, médico alienista de Burdeos, fueron nombrados por aclamación presidentes honorarios del Congreso.

58 GINÉ, J. (1884c): "Discurso de clausura del Certamen Frenopático de Nueva-Belén", en Primer Certamen Frenopático Español, Barcelona, La Academia, pp. 497-501.

59 Ibid., p. 499.
} 
PRIMER CERTAMEN FRENOPÁTICO ESPAÑOL (1883): ESTRUCTURA ASISTENCIAL Y...

frenopatía como ciencia biológica, sobre la que operamos materialmente "... nos declaramos partidarios del determinismo, no somos partidarios de la imputabilidad de las acciones frenopáticas, pero no aceptamos las exageraciones de los que piensan que los estimulos orgánicos ... induzcan completa irresponsabilidad, y en consecuencia, absoluta inculpabilidad"60. Asimismo, recalcó la advertencia de la falta de ley, que determinara los procedimientos relativos al ingreso y la función profiláctica de los manicomios.

La clausura del Congreso estuvo coronada por la inaguración de la estatua de Fray Juan Gilaberto Jofré (1350-1417), la lectura de la biografía de este personaje a cargo de Victor Azcarreta y Colau, miembro de la Comisión Organizadora, y la ordenación histórica de todos los manicomios fundados en el siglo XV.

A modo de conclusión parcial, es de destacar la preocupación de los alienistas acerca de la laguna legislativa existente, considerando que un denominador común en las diversas intervenciones fue el de reclamar de la administración un mayor papel de los profesionales en las reformas asitenciales. Esta cuestión quedó de un modo muy concreto expresada en el "Ensayo Médico-Administrativo sobre el ingreso y la estancia y salida de los enfermos de la mente en los asilos públicos y privados" de Giné y la propuesta de elevarlo al Excmo Director General de Beneficiencia y Sanidad así como en la petición del reconocimiento de la frenopatología como una disciplina específica a impartir en la enseñanza oficial teórica y práctica de la Medicina, expresada en una moción al Ministro de Fomento. Estos elementos reclamados, como se sabe, constituyen eslabones en el proceso de institucionalización de cualquier disciplina médica.

Como resumen, Domenech y Corbella resaltan el estilo moderno del Congreso: "no se improvisó, se anunció con tiempo, se convocaron premios que honradamente no se concedieron por falta de calidad y se recogieron las comunicaciones y se publicaron la actas"61. Sin embargo, todas las aspiraciones de aquellos profesionales no se verían cumplidas; ya que Galcerán, años más tarde, expondría una crítica sobre el Real Decreto del Ministerio de la Gobernación del 19 de mayo de 1885, considerándolo un retroceso sobre la legislación previa ${ }^{62}$. La falta de continuidad del evento y la escasa influencia del mismo en el ambiente médico y académico de la época no parece que se debiese, a nuestro entender, a errores organizativos, sino a una deficiente estructura administrativa y a una falta de voluntad política que impidieron durante muchos años el desarrollo de la psiquiatría como disciplina científica institucionalizada.

60 Ibid., p. 500.

61 DOMENECH, E. (1966), p. 207.

62 GALCERÁN, A. (1885): "Consideraciones críticas sobre el Real Decreto sobre la reglamentación de los manicomios", Revista Frenopática Barcelonesa, 5, pp. 125-132. 